\title{
Guidelines for supporting a pregnant patient with brain death: A case discussion and literature review
}

\author{
Lisa Rose Erlinger *1,2,3,4 \\ ${ }^{1}$ Midwestern University, Glendale, Arizona, United States \\ ${ }^{2}$ Wickenburg Community Hospital, Wickenburg, Arizona, United States \\ ${ }^{3}$ University of Missouri, Columbia, Missouri, United States \\ ${ }^{4}$ Southern Illinois University, Edwardsville, Illinois, United States
}

Received: October 30, 2016

DOI: $10.5430 /$ jnep.v7n8p86
Accepted: March 5, 2017

URL: https://doi.org/10.5430/jnep.v7n8p86

\begin{abstract}
Brain death implies irreversible cessation of brainstem function. While it is generally considered unethical and futile to support vital organs once brain death is diagnosed, patients who are both pregnant and brain dead complicate this issue. The appropriateness of continuing maternal somatic support to prolong gestation until delivery is an issue of debate. This paper reviews the literature and opens dialogue about the need for guidelines and recommendations in anesthesia care, including the ethics, legality, and cost of supporting pregnant patients who are brain dead, are in a persistent vegetative state (PVS), or are in a coma due to irreversible brain injury, in order to save the fetus. The review considers United States and international cases. Making a case for or against supporting these patients is outside the scope of this paper. Instead, this case report and literature review highlights the need for guidelines to assist health care professionals in providing care to for the pregnant patient who is brain dead.
\end{abstract}

Key Words: Ethics, Legal, Cost, Somatic support, Brain death

\section{INTRODUCTION}

Death of the brain implies irreversible cessation of brainstem function. Brain death (BD) as coma depasse was first defined by Mollaret and Goulon and remains the legally accepted diagnosis of death. ${ }^{[1]}$ It is generally considered unethical and futile to support vital organs when brain death is diagnosed. ${ }^{[2]}$ Patients who are in a persistent vegetative state (PVS), are in a coma, or are brain dead and pregnant complicate the issue of continued support because the fetus may be viable. As a result, the issue is fraught with questions, both ethical and legal. Making a case for or against supporting such patients is outside the scope of this paper. Instead, I focus on the gathering of information to develop nursing guidelines for nursing when caring for the neonate and pa- tient who is brain dead and on somatic support. The cases discussed took place in the United States and internationally.

While cases of pregnant patients who have been declared brain dead are rare, forty-three reported cases of maternal brain death, most with normal fetal outcomes, have been reported since 1979. Two review of literature studies have reported 31 of the 43 cases. ${ }^{[3,4]}$

At present, there are no guidelines describing the management of extended maternal somatic support; as a result, it is difficult to form conclusions about the best care for the somatic support of pregnant patients and their fetuses who are brain dead. Some literature considers the appropriateness of continuing maternal somatic support in order to prolong gestation until the fetus can be delivered. ${ }^{[1,2,4-6]}$ A national

*Correspondence: Lisa Rose Erlinger; Email: Lisa.Erlinger@ wickhosp.com; Address: Midwestern University, Glendale, Arizona, United States. 
registry could assist in making evidence based guidelines for the management of extended maternal somatic support.

This paper first considers the medical, ethical, cost, and legal issues surrounding such cases by considering a case report of brain death during a pregnant patient's first trimester. Eight cases of maternal brain death found in the literature are discussed. The conclusion provides suggestions for mandating a national registry to guide providers with the decisions around somatically supporting a pregnant mother.

\section{CASE discussion}

A 20 -year-old patient who was $12 \mathrm{H} 13$ weeks' pregnant was admitted to the hospital as trauma 1 MVA (motor vehicle accident). She was initially evaluated at an outside hospital as GCS (Glasgow coma scale) 14, but rapidly declined to GCS 3 and was intubated with a endotracheal tube. A computerized tomography (CT) scan showed acute intracranial subarachnoid hemorrhage. Two neurological evaluations, including two electroencephalograms (EEGs), were performed, and the patient was declared brain dead. Prior to death, the patient had signed a donor card, and this preference was indicated on her driver's license.

A task force was created to discuss the best options for the case. The case was carefully considered in a meeting that included, but was not limited to, the chairman of the Department of Obstetrics and Gynecology, the trauma surgeon, a member of the ethics committee, the chairman of the Department of Anesthesiology, the chief Certified Registered Nurse Anesthetist (CRNA), an associate professor in the Department of Obstetrics and Gynecology, the director of the Anesthesia Residency Program, a physician member of the Department of Anesthesia, and the Director of Nursing.

The mother's medical condition deteriorated quickly. The task force provided the patient's mother the details of the discussion with options. Those options included somatic support until a viable age of the fetus was reached or allowing organ donation followed by peaceful passing of the mother and fetus. The patient's mother chose to allow the fetus to remain with her daughter. The patient's organs were donated and the patient with her fetus died.

\subsection{Medical issues}

In caring for a pregnant patient who is brain dead, health care professionals must understand the unique medical issues facing the patient and fetus. The optimal period for delivering a viable and healthy infant in a normal pregnancy is 32 to 34 gestational weeks. Prior to week 24, the neonate would have a $20 \%$ to $30 \%$ chance for survival, with a $40 \%$ probability of severe neurological disorders. The prognosis

Published by Sciedu Press improves for neonates delivered between weeks 24 and 28, when the survival increases to $80 \%$, and the risk of neurological complications is $10 \%$. After gestational week 32 , the risk to the life and health of the fetus is the lowest, with a $98 \%$ survival rate and less than a $2 \%$ risk of neurological complications. ${ }^{[1,5,7]}$ These improvements are due to the progress made in critical care medicine in the past 30 years, including the development of cephalosporins and the evolution of extracorporeal membrane oxygenation (ECMO), which has advanced the viability of multiple organ retrieval.

In rare circumstances, a pregnant patient may be in a persistent vegetative state (PVS, be brain dead, or be comatose. In such cases, in patients who are past the threshold of fetal viability, that is, 24 weeks' gestation, the continuation of the pregnancy in utero to reach the optimal age of 32 weeks could increase the neonate's neurological and physical well-being. ${ }^{[5,6]}$ When the fetus is nonviable, that is, before 22 weeks, all parties must discuss whether to continue full somatic support of the mother so as to prolong the pregnancy and allow the fetus to mature, or to immediately discontinue mechanical ventilation and other chemical support. ${ }^{[8]}$

Between 1976 and 2003, 31 pregnant patients with fatal brain injury were somatically supported. ${ }^{[3,4]}$ In the 31 cases, four fetuses died, one fetus had undocumented complications, one court-ordered abortion was reported, and 25 fetuses survived. ${ }^{[1-23]}$ The frequency of unsuccessful support of pregnancies after maternal brain death is unknown, as few reports exist in the published literature. ${ }^{[8]}$ The longest reported duration of successful maternal somatic support following brain death is 107 days; this occurred in $1985 .^{[11,12]}$

Aggressive multisystem support is invariably required to care for a pregnant patient who is in a PVS, is brain dead, or is comatose. The Society of Critical Care Medicine, the American College of Chest Physicians, and the Association of Organ Procurement Organizations collaborated and wrote a consensus statement on this topic in 2015. ${ }^{[9]}$ The goal of the statement was to provide critical care practitioners with essential information and practical recommendations related to the management of potential organ donors, based on the available literature and expert consensus.

Multiple papers have been written to formulate resuscitation guidelines for the care of a pregnant patient who is in a PVS, is brain death, or is comatose. ${ }^{[1,3,5,8-10]}$ The likelihood of successfully maintaining maternal somatic function primarily depends on the duration of time required for the fetus to attain viability. ${ }^{[1,3,5,8-10]}$ Clinical interventions used in somatic support of pregnant patients who are in a PVS, are brain dead, or are in a coma due to irreversible brain injury include nursing care and anesthesia care. These interventions 
do not address the effects of somatic support on the fetus.

\subsection{Ethical issues}

Ethical issues arise in the case of a pregnant patient who is brain dead because the literature presents differing views on the subject. ${ }^{[1,2,4-6]}$ Understanding the many lines of thinking related to these ethical issues should provide health care professionals with a basis to care for patients who are brain dead and the fetus. Care may include providing education and support to families dealing with difficult decisions about the brain dead mother. The literature addresses three lines of ethical reasoning: maintaining the mothers' body as a "fetal incubator" is unethical; mothers who, prior to death, wished to donate their organs are "donating" their organs to the fetus; and the decision to somatically support the mother is a choice of the next of kin. ${ }^{[1,2,4-6]}$

Some professionals believe it is not ethical to maintain the mothers' body as a fetal incubator because this places the mother as a "fetal container" with no autonomous rights. ${ }^{[1]}$ This line of thinking asks "Who makes the decision to continue the somatic support in hopes of a viable fetus?"[1]

In this case report, prior to death, the mother had indicated a wish to donate her organs. Some literature argues that prolonged somatic support is organ donation, in which the fetus is the recipient. ${ }^{[1]}$ Since such catastrophic cases are so infrequent, the mother's preference is rarely known. This line of thinking speculates that, if the mother had not terminated the pregnancy early on, then she had the intent to carry the fetus to term.

Many papers emphasize that the decision to continue somatic support ultimately lies with the next of kin. ${ }^{[1,3,5]}$ In the case discussed, the father was unknown, and therefore the decision fell to the patient's mother who requested the fetus stay with the patient.

The religion or faith of the patient is also a consideration. The Catholic faith believes life must prevail over all things. ${ }^{[13]}$ Catholic ethics presume a human fetus at every stage to be a person possessing a right to life. ${ }^{[14]}$ The faith of our patient was not revealed. These beliefs may or may not and should or should not affect nursing care of the patient and the fetus. A complete review of religion preferences for somatic support is out of the scope of this paper but supports the need for guidelines.

A need to respect the body after death is present in the literature, but it is not clear that discontinuing somatic support to allow immediate somatic death and subsequent decomposition of a live fetus is more respectful or dignified than continuing support for the benefit of a fetus. ${ }^{[5]}$ A possible solution to this could be answered by using guidelines set for healthcare professional to assist in these decisions. The guidelines should consider the ethics related to patients who are brain dead and their fetus.

\subsection{Cost}

The costs involved with somatic critical care support, neonatal intensive care, and possible lifelong support of a neonate delivered with special needs should be part of the considerations. These are a direct concern for the families of pregnant patients who are brain dead, as well as the health care system. The most recent reported information found in the literature is from a 1996 paper. The paper reported that it cost $\$ 200,000$ to maintain a pregnant patient in a vegetative state from 14 to 31 weeks, followed by $\$ 100,000$ from neonate to 5 months of age. ${ }^{[15]}$

\subsection{Legal issues}

Legal issues can arise in the case of a pregnant patient who is brain dead. The legal rights of the fetus depend on the gestational age. These rights vary by country and are closely linked to the laws concerning abortion. Countries that have the greatest legal protection for the fetus either do not permit therapeutic abortion in any circumstances (e.g., Egypt, Chile, Malta, Iran, and the Philippines) or permit abortion only in circumstances in which pregnancy threatens the mother's life (e.g., Ireland; court approval needed in Nigeria, Mexico, Paraguay, and Venezuela). ${ }^{[5,16]}$ Many countries balance the legal rights of the fetus against the risk of serious damage to the mother's physical (e.g., Argentina, Ethiopia, Pakistan, Poland, and Thailand) and/or mental (e.g., Israel, Jamaica, Malaysia, New Zealand, Portugal, and Spain) health. ${ }^{[5]}$ The fetus may be awarded legal protection at 12 weeks' (e.g., Hungary), 14 weeks' (e.g., Austria, Belgium, Cambodia, France, Germany, and Romania), 18 weeks' (e.g., Sweden), or 24 weeks' (e.g., Singapore and the United States) gestation. ${ }^{[5]}$

In the United States, the question of whether fetuses are holders of rights and duties has been historically exercised by each state. Roe v. Wade and other Supreme Court opinions implicitly recognize this as a function of state sovereignty. ${ }^{[17]}$ In Roe v. Wade, the state of Texas argued that a fetus is a person who has a legal right to life within the language and meaning of the Fourteenth Amendment. ${ }^{[15]}$

In the case of a mother who is brain dead, the death certificate will state that the time of death occurs at the time brain death was diagnosed. This can, in itself, pose legal issues in cases in which a somatically supported mother "delivers" neonate months after her legal death. Furthermore, if the mother is considered legally dead, then the fetus poses no threat to her mental or physical well-being. ${ }^{[5]}$ This could 
give legal rights to the fetus in countries in which gestational age is independent or exceeded. ${ }^{[5]}$

\section{DISCUSSION}

Table 1 provides a comprehensive list of forty-three pregnant patients who were in a PVS, were brain dead, or were in a coma from 1976 to 2015 . In a systematic review of 30 cases between 1982 and 2010, the mean maternal age at time of BD was 26.5 years. ${ }^{[1]}$ The mean gestational ages at the time of BD and gestational age at delivery were 22 and 29.5 weeks, respectively. ${ }^{[1]}$ Another study added two additional patients from 1976 to $1979 .{ }^{[4]}$

From this cohort (1976-2015), twelve viable neonates were delivered and survived the neonatal period. Ms. L. was six months' gestation when she received the diagnosis of PVS Ms. L. was somatically supported for 51 days and delivered a normal neonate at 28 weeks' gestation. Patient 2 was six weeks' gestation when an accident left her in a PVS. She was somatically supported for 28 weeks and delivered a normal neonate at 34 weeks' gestation.

The following discussion will concern the eight cases found in the literature between 2010 and 2015. In Ireland, a mother in her twenties and 18 weeks' pregnant suffered a traumatic brain injury on November 29, 2014. The woman's parents wanted her to be taken off life support immediately, and they took legal action to force the hospital to remove her from somatic support. ${ }^{[18]}$ The law in Ireland is clear: According to the Eighth Amendment of the Constitution Act of 1983 the fetus has rights to life equal to those of the mother. ${ }^{[16]}$ Abortion is a criminal offense in Ireland under the Offences Against the Person Act of 1861. ${ }^{[16]}$ There is an effort to establish an exception to this law by allowing termination in cases of fatal fetal abnormalities. The minister for Children, James Reilly, believes this will be a matter for the next government because the current one has ruled out further referendums during its lifetime. ${ }^{[19]}$ Ironically, in this case, the High Court issued a ruling to terminate fetal life by stating it was in the best interest of the unborn neonate. ${ }^{[18]}$

Mr. M. of Texas found his wife unconscious at their home on November 26, 2013. She died of a pulmonary thrombosis and was 14 weeks' pregnant. It was suspected that she had not been breathing for an hour. Mr. M. knew his wife would not want to be kept alive artificially. Mr. M. fought a Texas law that says "you cannot withhold or withdraw lifesustaining treatment for a pregnant patient" and eventually won a lawsuit in late January 2014, because his attorneys provided evidence of multiple fetal deformities, including heart problems. ${ }^{[20]}$

Ms. B. of Victoria, British Columbia was declared brain dead in December 2013 after cerebral hemorrhage. She was 22 weeks' pregnant. Mr. B. wanted to continue artificially supporting his wife in hopes of a healthy neonate. Somatic support was continued for 12 weeks, and the neonate was delivered in February 2014 by cesarean section at the gestational age 34 weeks and did well. Ms. B. was allowed to die within hours of delivery. ${ }^{[20]}$

Ms. J., a 22-year-old pregnant woman, presented to a hospital in Newark, Delaware in 2010 and was diagnosed with anoxic brain injury due to a heroin overdose and entered into a PVS. ${ }^{[21]}$ At the time, the patient was 11 weeks' gestation and had been found unresponsive by her boyfriend. It was reported as unclear if the patient was ever pulseless or was primarily suffering respiratory arrest. ${ }^{[21]}$

A multidisciplinary approach was used from the start. Ethical consultation with the patient's parents and grandparents laid the groundwork for future decisions regarding the patient and the fetus and to determine whether the mother or the fetus would be the priority. The obstetricians suggested that the likelihood of the neonate suffering from either the drug overdose or lack of oxygen was not significant. It was clearly stated that the patient was expected to be able to sustain this pregnancy to near term and deliver a healthy neonate. At 32 weeks' gestation, the patient delivered a healthy $6 \mathrm{lb}$. and 4 oz. neonate by cesarean section.

A Twenty-two-year-old was 22 weeks' gestation when she collapsed at her home in Omaha, Nebraska in February 2015. ${ }^{[22]}$ A CT scan showed she had suffered a fatal intracranial hemorrhage, and she was declared brain dead. Ms. P's family urged doctors to do everything possible to save the fetus. Ms. P. was somatically supported for 54 days (approximately 7 weeks), at which time her body began to shut down, forcing an emergency cesarean section. The neonate was delivered at 29 weeks' gestation, without any serious complications. Afterward, Ms. P's family donated her organs. Ms. P was the first person in the United States since 1999 to be kept on somatic support.

While rare, cases do exist in which a pregnant mother is declared to be in a VGS, be brain dead, or be comatose. The literature shows mothers can be somatically supported and deliver a viable neonate.

\section{Conclusion}

Brain injury during pregnancy raises difficult ethical, medical, and legal issues. Cases involving brain death during pregnancy require the management of an intensive multidisciplinary approach using expertise in the areas of cardiology, critical care, psychology, obstetrics and gynecology, neonatology, ethics, neurology, and social work. 
Table 1. Forty-three pregnant patients, who are in a PVS, are brain dead, or in a coma, 1976-2015

\begin{tabular}{|c|c|c|c|c|c|c|}
\hline Year & $\begin{array}{l}\text { Country of } \\
\text { Origin }\end{array}$ & Maternal Age & $\begin{array}{l}\text { Gestational } \\
\text { Age at Event }\end{array}$ & $\begin{array}{l}\text { Time From Event } \\
\text { Until Delivery }\end{array}$ & Delivery Age & Neonatal Outcome \\
\hline 1976 & - & 26 & 6 months & 51 days & 8 months & Normal \\
\hline 1979 & - & 30 & 6 weeks & 28 weeks & 34 weeks & Normal at 2 years \\
\hline 1982 & - & 30 & 18 weeks & 10 days & - & Spontaneous abortion \\
\hline 1982 & USA & 24 & 23 weeks & 24 days & 29 weeks & $\begin{array}{l}\text { Fetal hydantoin syndrome at } 3 \\
\text { months }\end{array}$ \\
\hline 1984 & - & 34 & 17 weeks & 18 weeks & 35 weeks & Mild delay at 24 months \\
\hline 1985 & - & 28 & 14 weeks & 14 weeks & 34 weeks & Normal at 21 months \\
\hline 1985 & Finland & 31 & 21 weeks & 10 weeks & 31 weeks & Normal at 8 months \\
\hline 1986 & - & 39 & 22 weeks & 14 weeks & 34 weeks & Viable \\
\hline 1988 & - & 20 & 5 months & 118 days & 37 weeks & Normal at 2 years \\
\hline 1988 & USA & 27 & 22 weeks & 9 weeks & 31 weeks & Normal at 18 months \\
\hline 1989 & USA & 30 & 15 weeks & 117 days & 32 weeks & Normal at 11 months \\
\hline 1992 & Italy & 25 & 15 weeks & 49 days & - & Intrauterine death \\
\hline 1993 & USA & 31 & 27 weeks & 44 days & 33 weeks & Viable \\
\hline 1993 & Germany & 18 & 13 weeks & 38 days & - & Spontaneous abortion at 19 weeks \\
\hline 1993 & - & 24 & 13 weeks & 168 days & 37 weeks & Normal at home limited speech \\
\hline 1993 & Switzerland & 20 & 20 weeks & 3 days & - & Intrauterine death \\
\hline 1994 & Germany & 18 & 14 weeks & 5 weeks & - & Spontaneous abortion \\
\hline 1995 & USA & 35 & 30 weeks & 2 days & 30 weeks & Viable \\
\hline 1995 & Spain & 25 & 27 weeks & 1.5 days & 27 & Normal at 14 months \\
\hline 1996 & - & 24 & 14 weeks & 17 weeks & 31 weeks & Developmental delay \\
\hline 1997 & USA & 25 & 25 weeks & 25 days & 28 weeks & \\
\hline 1997 & USA & 25 & 25 weeks & 54 days & 31 weeks & \\
\hline 1997 & - & 34 & 22 weeks & 77 days & 33 weeks & Early-onset sepsis, normal \\
\hline 1998 & USA & $\begin{array}{l}\text { Range from } 15 \text { to } \\
45 \text { (11 cases) }\end{array}$ & - & - & - & 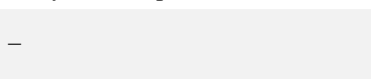 \\
\hline 1999 & Chile & 26 & 17 weeks & 98 days & 31 weeks & - \\
\hline 1999 & - & 23 & 12 weeks & Several months & - & - \\
\hline 1999 & - & 18 & 17 weeks & 112 days & 33 weeks & - \\
\hline 1999 & - & 20 & 16.5 weeks & 100 days & 31 weeks & - \\
\hline 2000 & - & 29 & 12 weeks & 161 days & 35 weeks & - \\
\hline 2000 & - & 23 & 16 weeks & 100 days & 31 weeks & Normal at 18 months \\
\hline 2001 & - & 22 & 4 weeks & 2004 & 33 weeks & Normal at 12 months \\
\hline 2002 & - & 33 & 15 weeks & 63 days & $24-1 / 7$ weeks & Survived 24 hours \\
\hline 2004 & Ireland & 26 & 13 weeks & 8 days & - & Intrauterine death at 14 weeks \\
\hline 2006 & UK & 33 & 26 weeks & 14 days & 28 weeks & $\begin{array}{l}\text { Male, } 1285 \mathrm{gr} \text {, breathing } \\
\text { difficulties Normal at } 24 \text { months }\end{array}$ \\
\hline 2006 & Brazil & 40 & 25 weeks & 25 days & 29 weeks & $\begin{array}{l}\text { Male } 815 \text { gr Apgars:9/10 Normal } \\
\text { at } 3 \text { months }\end{array}$ \\
\hline 2008 & Argentina & 29 & 17 weeks & 56 days & 25 weeks & $\begin{array}{l}450 \text { gr Premature Birth } \\
\text { complication, Candida infection } \\
\text { Died at day } 30\end{array}$ \\
\hline $\begin{array}{l}\text { February } \\
2010\end{array}$ & USA & 22 & 11 weeks & & 32 weeks & Healthy female \\
\hline 2013 & Hungary & - & - & - & $\begin{array}{l}\text { Viable delivery after } 90 \\
\text { days of somatic support }\end{array}$ & - \\
\hline 2014 & Hungary & - & - & - & $\begin{array}{l}\text { Viable delivery after } 60 \\
\text { days of somatic support }\end{array}$ & - \\
\hline $\begin{array}{l}\text { January } \\
2014\end{array}$ & USA & - & 14 weeks & - & $\begin{array}{l}\text { Abnormal fetal growth, } \\
\text { mother removed from } \\
\text { somatic support }\end{array}$ & - \\
\hline $\begin{array}{l}\text { February } \\
2014\end{array}$ & USA & - & 22 weeks & & 34 weeks & - \\
\hline $\begin{array}{l}\text { December } \\
2014\end{array}$ & Ireland & $20 \mathrm{~s}$ & 18 weeks & & $\begin{array}{l}\text { Court removed somatic } \\
\text { support of viable fetus }\end{array}$ & - \\
\hline 2015 & Poland & 30 & 22 weeks & & 28 weeks & - \\
\hline 2015 & USA & 22 & 22 weeks & & 29 weeks & - \\
\hline
\end{tabular}

Notes. Not every source reported the same information, and therefore data are missing. Source: ${ }^{[1,3-5,8-10,12-14,20-22]}$. 
Forty-three cases of somatic support were reported from 1976 to $2015 .^{[1-6,8-22]}$ Thirty-two viable fetuses were delivered and survived the neonatal period. Three were not delivered; one mother was removed from support due to abnormal fetal growth; one mother was removed from support by a court order, leading to fetal demise; and one family made the decision to remove the mother from support, leading to fetal demise.

The Society of Critical Care Medicine, American College of Chest Physicians, and the Association of Organ Procurement developed a consensus statement to help guide the care of a pregnant patient who is in a PVS, who is brain death, or is in a coma. ${ }^{[7]}$ Efforts should continue in order to include obstetric and neonatal considerations for cases in which a pregnant brain-injured patient is on somatic support. Guidelines that take these complex medical issues into account are necessary to provide the best care to patients who are brain dead with a fetus. Guidelines are needed for the appropriate nursing care of the pregnant patient and the fetus in cases where the family has decided to somatically support the mother until the delivery of the infant. Nurses need guidelines to assist in not instilling one's own beliefs. Evidence-based guidelines to justify maximizing or minimizing health care costs are needed. Nurses need guidelines to navigate these extensive legal issues. Nursing care may need to focus primarily on the fetus rather than the mother or the mother rather than the fetus, or both.

This paper does intend to make an argument for somatic support, but acknowledges that somatic support does occur in some cases and that it is associated with complex medical, ethical, and legal issues that may change the focus of nursing care. In these cases, high-quality care to the patient and fetus is still essential. Unfortunately, it is difficult to make conclusions concerning care in the absence of reports of somatic support and successful deliveries of live fetuses in these pregnancies. Since only a few cases describe the management of extended maternal somatic support, it would be beneficial to have a national registry of such cases. A national registry could provide the evidence necessary to make evidence-based guidelines for the management of care during extended maternal somatic support.

\section{CONFLicts OF InTEREST Disclosure}

The author declares that there is no conflict of interest.

\section{REFERENCES}

[1] Esmaeilzadeh M, Dictus C, Kayvanpour E, et al. One life ends, another begins: management of a brain dead pregnant mother-a systematic review. BMC Medicine. Nov 2010; 8(74): 2-11. https: //doi.org/10.1186/1741-7015-8-74

[2] Lane A, Westbrook A, Grady D, et al. Maternal brain death: medical, ethical and legal issues. Intensive Care Med. $2004 \mathrm{Jul}$; 30(7): 14841486. PMid:15107974 https ://doi .org/10.1007/s00134-004 $-2305-6$

[3] Feldman DM, Borgida AF, Rodis JF, et al. Irreversible maternal brain injury during pregnancy: a case report and review of the literature. Obstet Gynecol Surv. 2000 Nov; 55(11): 708-714. PMid:11075735 https://doi.org/10.1097/00006254-200011000-00023

[4] Bush MC, Nagy S, Berkowitz RL, et al. Pregnancy in a persistent vegetative state: case report, comparison to brain death, and review of literature. Obstet Gynecol Surv. 2003 Nov; 58(11): 738-748. PMid:14581825 https://doi.org/10.1097/01.0GX.0000093 268.20608.53

[5] Farragher RA, Laffey JG. Maternal brain death and somatic support. Neurocritical Care. 2005; 3: 99-106. https://doi.org/10.138 $5 / \mathrm{NCC}: 3: 2: 099$

[6] Dillon WP, Lee RV, Tronolone MJ, et al. Life support and maternal death during pregnancy. JAMA. 1982; 248: 1089-1091. https://doi.org/10.1001/jama.1982.03330090059030

[7] Wawrzyniak J. Continuation of pregnancy in a woman with critical brain injury. Anaesthesiology Intensive Therapy. 2014. 42(1): 40-44.

[8] Mallampalli A, Guy E. Cardiac arrest in pregnancy and somatic support after brain death. Critical Care Medicine. 2005; 33(10 Suppl): S325-S331. PMid:16215355 https://doi.org/10.1097/01.C CM. 0000182788.31961 .88

Published by Sciedu Press
[9] Kotloff RM, Blosser S, Fulda GJ, et al. Management of the Potential Organ Donor in the ICU: Society of Critical Care Medicine/American College of Chest Physicians/Association of Organ Procurement Organizations Consensus Statement. Critical Care Medicine. 2015; 43(6): 1291-1325. PMid:25978154 https://doi.org/10.1097/ CCM. 0000000000000958

[10] Powner DJ, Bernstein IM. Extended somatic support for pregnant women after brain death. Critical Care Medicine. 2003; 31(4): 12411249. PMid:12682499 https://doi .org/10.1097/01. CCM. 000 0059643.45027 .96

[11] Heikkinen JE, Rinne RI, Alahuhta SM, et al. Life support for 10 weeks with successful fetal outcome after fatal maternal brain damage. BMJ (Clinical Research Edition). 1985; 290(6477): 1237-1238. https://doi.org/10.1136/bmj.290.6477.1237

[12] Bernstein IM, Watson M, Simmons GM, et al. Maternal brain death and prolonged fetal survival. Obstetrics and Gynecology. 1989; 74(3 Pt 2): 434-437.

[13] Bosch X. Pregnancy of brain-dead mother to continue. Lancet. 1999; 354(9196): 2145. https://doi.org/10.1016/S0140-6736(05 ) $77058-6$

[14] Hazel M. Bioethics for clinicians: 27. Catholic bioethics. CMAJ. 2001; 165(2): 189-192.

[15] Webb GW, Huddleston JF. Management of the pregnant woman who sustains severe brain damage. Clinics in Perinatology. 1996; 23(3): 453-464. PMid:8884119

[16] Aoife B. Explainer: what is the 8th amendment? 2014; Available from: http://www. thejournal.ie/what-is-the-eight - amendment-abortion-1625596-Aug2014/

[17] Gregory R. Unborn children as constitutional persons. Issues in Law \& Medicine. 2010; 25(3): 185-273. 
[18] Ertelt S. Court allows hospital to kill brain-dead pregnant mom's 18 week unborn baby. 2014; Available from: http://www. lifenews .com/2014/12/26/court-allows-hospital-to-kill-bra in-dead-pregnant-moms-18-week-unborn-baby/

[19] Pollak S, Griffin D. Repeal of the eighth amendment is 'very do-able'. 2015; Available from: http: //www.irishtimes.com/news/social-affairs/repeal-o f-the-eighth-amendment-is-very-do-able-1.2225166

[20] Payne E. Doctors keep brain dead pregnant woman on life support until baby's birth. 2014; Available from: http://www.cnn.com/2014/02/04/world/americas/ca nada-brain-dead-woman/index.html
[21] Abazzia C, Adamo F, Gil B, et al. In the name of good intentions: nurses perspectives on caring for a pregnant patient in a persistent vegetative state. Critical Care Nurse. 2010; 30(1): 40-46. PMid:20124019 https://doi.org/10.4037/ccn2010816

[22] Boyle D. Brain dead woman gives birth to miracle baby after doctors keep her alive on a ventilator for seven weeks-then allow her to pass away. 2015; Available from: http://www.dailymail.co.uk/news/article-3063170/D octors-moms-body-functioning-baby-survive.html

[23] Batar I. New abortion law in Hungary. Entre Nous Cph Den. 1993 Jun; (22-23): 17. PMid:12222239 